
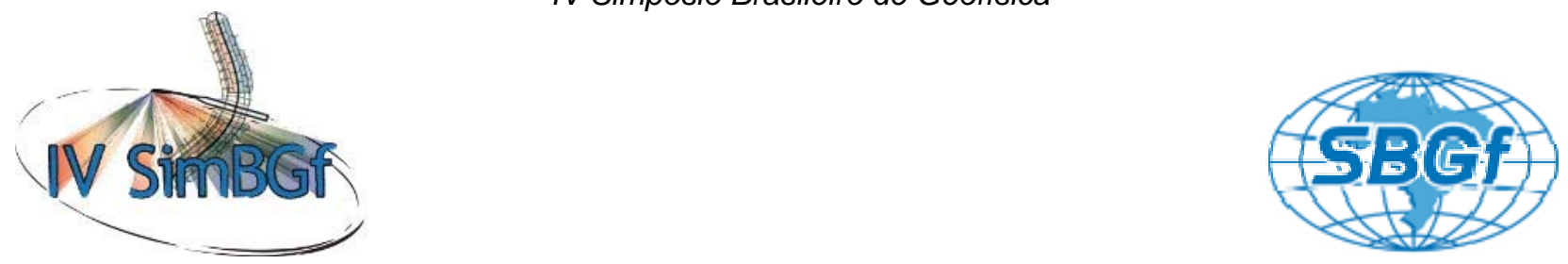

\title{
RELAÇÃO EMPÍRICA ENTRE O FLUXO GEOTÉRMICO E A IDADE DAS PROVÍNCIAS TECTỐNICAS BRASILEIRAS.
}

\author{
, Eric de O. Corrêa, Raphael T. Valente e Roberto R. Cardoso
}

Copyright 2010, SBGf - Sociedade Brasileira de Geofísica

Este texto foi preparado para a apresentação no IV Simpósio Brasileiro de Geofísica, Brasília, 14 a 17 de novembro de 2010. Seu conteúdo foi revisado pelo Comitê Técnico do IV SimBGf, mas não necessariamente representa a opinião da SBGf ou de seus associados. É proibida a reprodução total ou parcial deste material para propósitos comerciais sem prévia autorização da SBG

\section{Resumo}

O presente trabalho apresenta valores médios de fluxo geotérmico, para as províncias tectônicas brasileiras com diferentes idades geológicas, obtidos a partir da análise de dados de perfilagem térmica agrupados segundo a idade geológica da província tectônica do local onde a medição foi realizada. Os resultados obtidos indicam um fluxo médio de $81,3 \mathrm{~mW} / \mathrm{m}^{2}$ para províncias cenozóicas, $53,5 \mathrm{~mW} / \mathrm{m}^{2}$ para províncias mesozóicas, $42,8 \mathrm{~mW} / \mathrm{m}^{2}$ em províncias paleozóicas, $34,4 \mathrm{~mW} / \mathrm{m}^{2}$ em províncias proterozóicas e $31,5 \mathrm{~mW} / \mathrm{m}^{2}$ nas províncias arqueanas. Tais valores de fluxo geotérmico resultados são compatíveis com os resultados obtidos nos trabalhos de Polyak and Smirnov (1968) e Hamza and Verma (1969) que realizaram estudos semelhantes para a América do Norte, Europa, Austrália e Oceania respectivamente. Também foram calculados valores de condutividade térmica média para cada província, os valores obtidos estão compreendidos numa faixa desde $2,1 \mathrm{~W} /{ }^{\circ} \mathrm{Cm}$ para províncias arqueanas, proterozóicas e paleozóicas, 2,5 $\mathrm{W} /{ }^{\circ} \mathrm{Cm}$ em províncias mesozóicas e 2,7 para províncias cenozóicas. Também é apresentada uma relação empírica, para cálculo do fluxo geotérmico teórico, obtida através do ajuste aos valores médios de fluxo geotérmico. Através desta relação empírica é possível realizar representações do fluxo geotérmico sem a necessidade de interpolações matemáticas em áreas onde não existam dados de fluxo geotérmico.

\section{Introdução}

A densidade de dados de fluxo geotérmico no Brasil é caracterizada por uma distribuição espacial irregular. Este fato, que também ocorre em outros continentes como a África, por exemplo, faz com que representações do campo geotérmico, seja em escala global, ou em escala regional, apresentem regiões bastante extensas com valores calculados, durante processo de gridagem, por um interpolador numérico. Porém, as variações laterais do fluxo geotérmico não podem ser representadas por equações matemáticas, uma vez que tais variações são caracterizadas por variações das propriedades físicas e geológicas da região, como por exemplo, a condutividade térmica ou pelo tempo de relaxamento da distribuição de temperaturas após um evento termo-tectônico. Até a presente data, vários trabalhos de mapeamento de fluxo geotérmico (Hamza e

Munhoz-1996, Gomes e Hamza-2006) foram realizados fazendo-se uso de interpolações numéricas em áreas desprovidas de dados experimentais. A figura (1) mostra as variações laterais do fluxo geotérmico brasileiro e a distribuição dos dados experimentais.

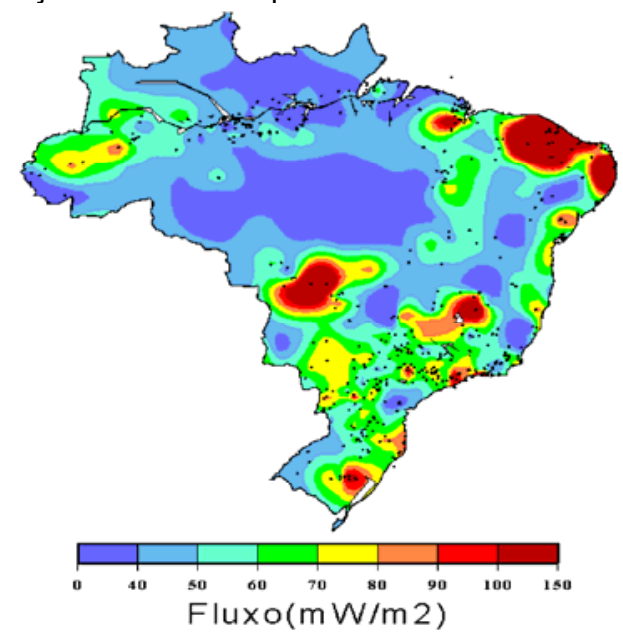

Figura (1) - Representação do Fluxo Geotérmico brasileiro. Os pontos pretos mostram a localização dos dados experimentais.

Observando a figura (1) é possível perceber que vastas regiões do território brasileiro são desprovidas de dados de fluxo geotérmico. Outra característica importante é a não uniformidade na densidade de dados, o que torna o processo de representação da variação de fluxo geotérmico, e conseqüentemente sua interpretação, ainda mais complexa. A solução para estes casos é a utilização de interpoladores numéricos, geralmente contidos no próprio aplicativo que gera o mapa. Os interpoladores mais utilizados em geotermia são: "Mínima Curvatura" e o "Inverso do Quadrado da Distância".

\section{Relação Idade Tectônica X Fluxo Geotérmico.}

A relação entre a idade tectônica e o fluxo geotérmico parte do princípio de que as rochas continentais se diferenciam do manto subjacente e que, no decurso desta diferenciação, o Urânio, o Tório e o Potássio foram seletivamente removidos do manto e concentrados em altos níveis da crosta devido ao magmatismo. É muito provável que, nas províncias Cenozóicas, a maior parcela do fluxo geotérmico que chega à superfície tem origem magmática. Dessa forma, o decaimento do fluxo de calor na superfície tem relação direta com a idade do local 
Relação Empírica Entre o Fluxo Geotérmico e a Idade das Províncias Tectônicas Brasileiras.

(província), do tamanho do corpo magmático, do grau de metamorfismo e do grau de empobrecimento dos elementos radioativos. Polyak and Smirnov (1968) calcularam o fluxo de calor empírico para regiões da América do Norte com base nas idades das principais províncias tectônicas. Hamza and Verma (1969) realizaram trabalho semelhante para a África, Austrália e Índia. Uma compilação dos resultados obtidos em ambos os trabalhos estão apresentados na tabela(1).

Tabela (1) - Valores médios de fluxo geotérmico, Polyak and Smirnov (1968) e Hamza and Verma (1969).

\begin{tabular}{|l|c|c|c|c|c|}
\cline { 2 - 7 } \multicolumn{1}{c|}{} & \multicolumn{5}{c|}{ Fluxo Geotérmico } \\
\hline \multicolumn{1}{c|}{ Idades } & N. America & Austrália & Europa & S. America & Ásia \\
\hline Cenozóico & 75 & 80 & 78 & 81 & 63 \\
\hline Mesozóico & 80 & - & - & 54 & 73 \\
\hline Escudos Paleozóicos & 62 & 58 & 67 & 43 & 56 \\
\hline Escudos Proterozóicos & 55 & 73 & 38 & 34 & 45 \\
\hline Escudos Arqueanos & 41 & 43 & - & 32 & 36 \\
\hline
\end{tabular}

Discrepâncias entre valores obtidos para uma mesma idade tectônica ocorrem devido a variações, como temperatura e pressão, no ambiente de formação das rochas.

\section{Idade das Províncias Tectônicas Brasileiras}

A figura (2) mostra o mapa com as idades das províncias tectônicas no território brasileiro (CPRM 2001).

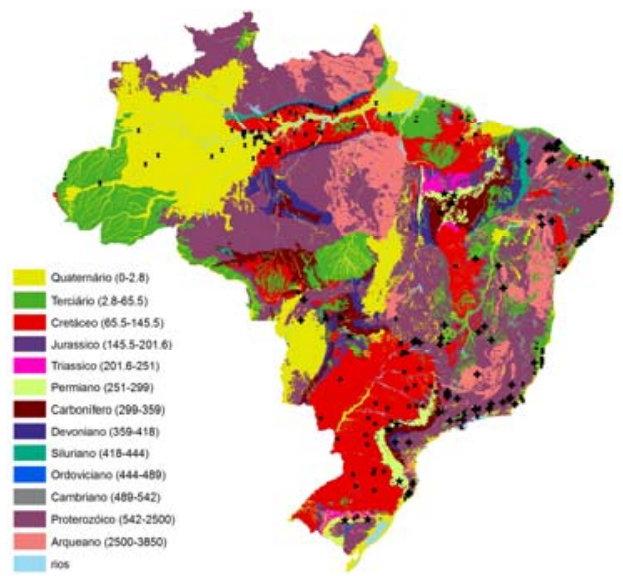

Figura (2) - Idade das Províncias Tectônicas no Brasil. As marcações em preto mostram a localização dos dados experimentais separados por província.

No mapa acima estão apresentadas unidades que caracterizam regime tectônico compressivo, unidades que caracterizam regime tectônico distensivo (intra-placa e margem passiva) e coberturas superficiais e permite uma leitura intuitiva da evolução geotectônica do Brasil ao longo do tempo geológico.

\section{Fluxo Geotérmico das Províncias Tectônicas.}

Os dados experimentais de gradiente geotérmico utilizados no presente trabalho fazem parte do acervo de dados geotérmicos do laboratório de geotermia do Observatório Nacional (ON - MCT). Foi utilizado um total de 936 dados agrupados segundo a idade da província tectônica de onde foi realizada a perfilagem térmica, tabela (3). No presente trabalho, apenas levantamentos CVL e BHT foram utilizados por se tratarem de métodos de levantamento geotérmico com maior grau de confiabilidade.

Tabela (3) - Valores médios de gradiente $\left(\Gamma-{ }^{\circ} \mathrm{C} / \mathrm{km}\right)$, condutividade térmica $\left(\mathrm{k}-\mathrm{W} / \mathrm{m}^{\circ} \mathrm{C}\right)$ e fluxo geotérmico ( $\mathrm{q}$ $\mathrm{mW} / \mathrm{m}^{2}$ ) das províncias tectônicas. Valores calculados para cada Período e Era geológica.

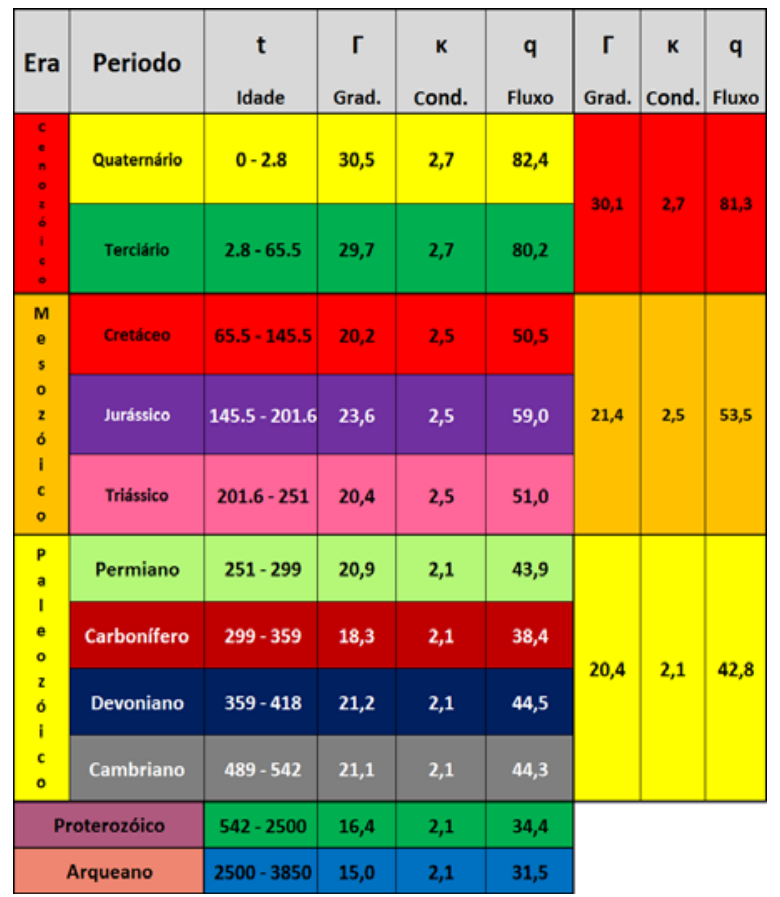

Conforme previsto, o fluxo geotérmico é menor em províncias com idades maiores, figura (3). Para províncias Arqueanas, o valor médio de fluxo geotérmico para o Brasil é da ordem de $32 \mathrm{~mW} / \mathrm{m}^{2}$ com condutividade média de $2,1 \mathrm{~W} / \mathrm{m}^{\circ} \mathrm{C}$. Na América do Norte, o valor encontrado foi de $41 \mathrm{~mW} / \mathrm{m}^{2}$, na Austrália $43 \mathrm{~mW} / \mathrm{m}^{2}$ e na Ásia $36 \mathrm{~mW} / \mathrm{m}^{2}$. Em províncias Cenozóicas, o fluxo médio é da ordem de $81,3 \mathrm{~mW} / \mathrm{m}^{2}$, contra $75 \mathrm{~mW} / \mathrm{m}^{2}$ na América do Norte, $80 \mathrm{~mW} / \mathrm{m}^{2}$ para a Austrália, $78 \mathrm{~mW} / \mathrm{m}^{2}$ na Europa e $63 \mathrm{~mW} / \mathrm{m}^{2}$ na Ásia. Em províncias Paleozóicas o fluxo médio obtido foi de 42,8 $\mathrm{mW} / \mathrm{m}^{2}$ e $53,5 \mathrm{~mW} / \mathrm{m}^{2}$ para províncias Mesozóicas.

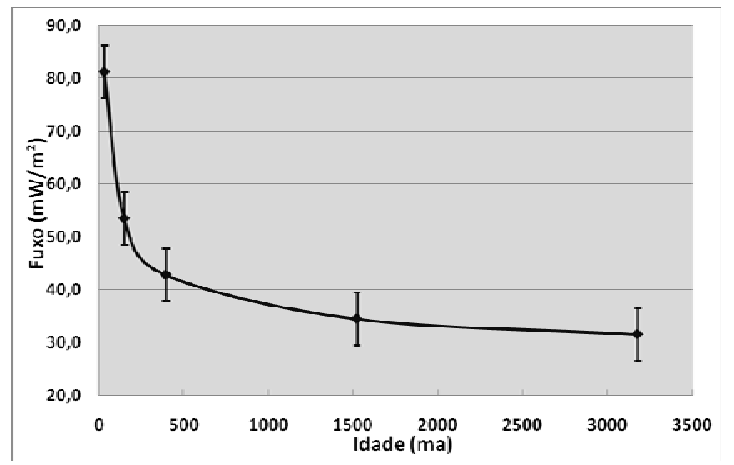

Figura (3) - Decaimento do fluxo geotérmico com a idade da província tectônica no território brasileiro. 


\section{Relação Empírica do Fluxo Geotérmico no Brasil em Função da Idade Tectônica.}

Equações que descrevem o comportamento temporal do fluxo geotérmico, obtidas a partir de soluções da equação de difusão de calor, aplicada nos processos de resfriamento da crosta continental e oceânica, geralmente, possuem soluções que dependem do inverso da raiz quadrada do tempo (Carslaw and Jaeger - 1959 e Stein and Stein - 1992). Sendo assim, pode-se supor que a variação do fluxo geotérmico com a idade da província tectônica possua uma relação semelhante. No caso dos resultados de fluxo de calor médio obtidos nesse trabalho, a relação que melhor se ajusta ao gráfico da figura (3) é:

$$
q(t)=\frac{310}{\sqrt{t}}+27(1)
$$

Os valores de fluxo de calor obtidos com a utilização da equação (1) estão representados pela curva vermelha da figura (4).

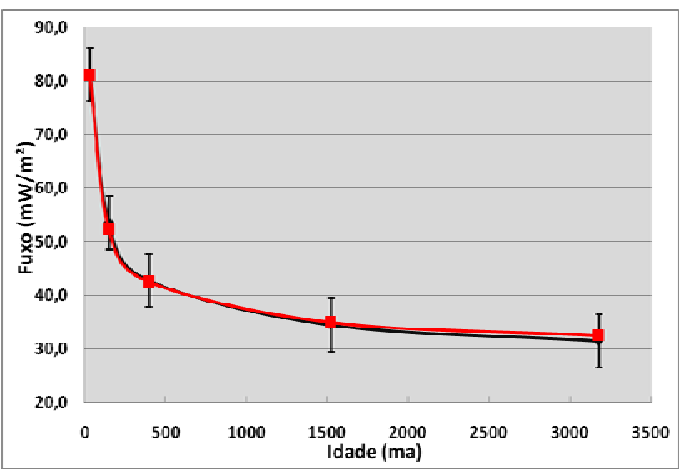

Figura (4) - Ajuste dos valores médios de fluxo geotérmico a partir da relação empírica descrita pela equação (1)

Pode-se notar que a curva vermelha da figura (4) obtida a partir da equação (1) se ajusta com excelente correlação aos valores médios de fluxo apresentados na tabela (3). É possível notar que a equação (1) é composta de duas parcelas, a primeira representa um estado transitório do fluxo geotérmico, causados por tectonismos regionais e locais, a segunda parcela o estado estacionário, representado um fluxo geotérmico remanescente, existente desde a formação da crosta terrestre. $O$ agrupamento dos períodos em eras geológicas, com seus respectivos intervalos de fluxo geotérmico, obtidos pela equação (1), pode ser observado na figura (7). Os valores de fluxo geotérmico apresentados no mapa da figura (7) foram calculados nos limites iniciais e finais de cada era geológica. Por isso, regiões extensas do período cenozóico e mesozóico aparecem todas com um mesmo padrão de cor. É possível aumentar a resolução se forem conhecidas idades intermediárias em regiões pertencentes a essas Eras geológicas.

\section{Resultados e Discussões.}

Uma comparação direta entre os mapas das figuras (1) e (7), mostra que o uso de interpolações numéricas na confecção de mapas geotermais induz perfis não compatíveis com as estruturas geológicas. Com o emprego da equação (1) e conforme apresentado pela figura (7), este quadro é totalmente alterado. É possível perceber, a partir de agora, os delineamentos das regiões com valores elevados de fluxo geotérmico, tanto em macro quanto em micro escalas. Por exemplo, se for levada em consideração as escalas de cores utilizadas para representar o fluxo geotérmico, os valores elevados de fluxo nas regiões norte e centro-oeste estão representados nas figuras (1) e (7), porém diferentemente da figura (1), em que as anomalias geotérmicas tendem formarem círculos, na figura (7) estas anomalias seguem os perfis geológicos.

A figura (5) mostra um exemplo, em micro-escala, do fluxo geotérmico na área da bacia de Taubaté obtido a partir da utilização da equação (1).

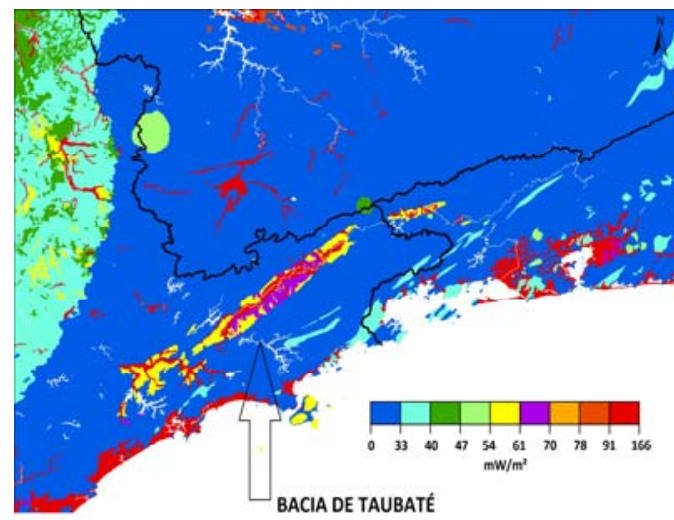

Figura (5) - Fluxo Geotérmico na Bacia de Taubaté.

É possível perceber que a anomalia geotérmica está direcionada ao longo do eixo longitudinal da Bacia de Taubaté, acompanhando as feições geológicas. Também estão representadas nesta figura, as anomalias geotérmicas das bacias de Resende e São Paulo.

Outro local de interesse geotérmico é a região que compreende os municípios de Caldas Novas e Rio Quente no estado de Goiás, esta região é conhecida internacionalmente pelas suas fontes hidrotermais, figura (6). O município de Rio Quente possui uma vazão d'água de cerca de $6000 \mathrm{~m}^{3} / \mathrm{h}$ com temperaturas entre 34 e 42 ${ }^{\circ} \mathrm{C}$.

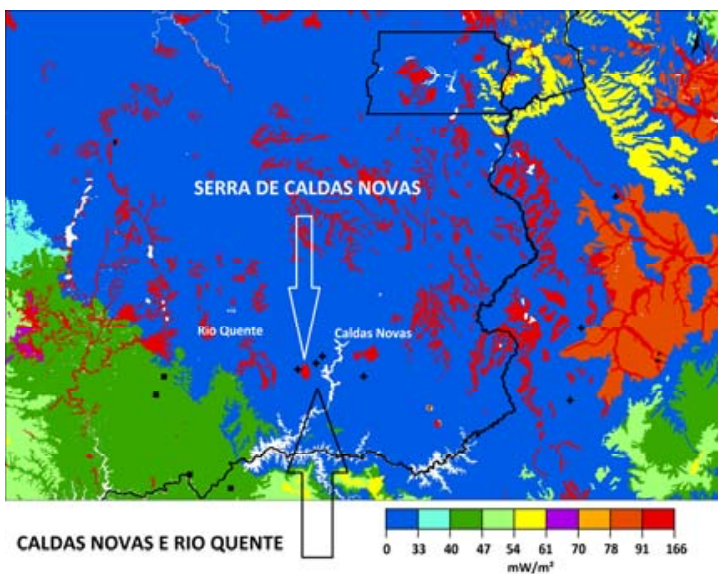

Figura (6) - Fluxo Geotérmico na Região de Caldas Novas e Rio Quente - GO. 
Esses municípios são separados pela Serra de Caldas Novas, ver figura (6). Nota-se que, apesar de estarem numa região de baixo fluxo geotérmico, sua proximidade com a Serra de Caldas Novas, de idade cenozóica e, portanto, caracterizada por um alto fluxo geotérmico, faz com que os valores experimentais de fluxo nestes municípios sejam elevados. Uma explicação para este fato pode estar numa possível combinação de efeitos causados por circulações hidrotermais, com origem na Serra de Caldas Novas, e uma propagação lateral de calor.

Outra característica importante apresentada pela figura (7) é a não existência de uma extensa anomalia na região nordeste, tal anomalia está representada em todos os mapas geotermais. Porém, uma análise detalhada na geologia desta região, mostra que, não deveriam existir valores elevados de fluxo geotérmico em regiões afastadas do litoral, e que a representação, de altos valores de fluxo em mapas geotermais, é oriunda de interpolações numéricas.

\section{Agradecimentos}

Os autores Eric de O. Corrêa e Raphael T. Valente participam do Programa de Iniciação Científica do Observatório Nacional financiado pelo Cnpq - Conselho Nacional de Desenvolvimento Científico e Tecnológico.

\section{Referências}

B. G. Polyak and Ya. B. Smirnov, Relationship between terrestrial heat flow and the tectonics of continents, Geotectonics (1968) $205-213$.

Carslaw, H.S., Jaeger, J.C., 1959, Conduction of heat in solids. $2^{\text {nd }}$ ed., Oxford University Press, New York.

Gomes, A.J.L e Hamza, V. M. 2005, Gradiente e Fluxo Geotérmico do Estado de Santa Catarina $9^{\text {th }}$ International Congress of the Brazilian Geophysical Society, Salvador, Brazil, 6 pages.

Hamza, V.M., and Muñoz, M., 1996, Hat Flow Map of South America. Geothermics, V.I25, nº 6, oo. 599-646.

Hamza, V. M., Verma, R. K., 1969, The Relationship of Heat Flow with Age of Basement Rocks, Bull. Volcan., Vol XXXIII-1, p. 123-152

Stein, C. Stein, S., 1992, A model for the global variation in oceanic depth and heat flow with lithospheric age. Nature, 359:123-129.

Luiz Augusto Bizzi, Carlos Schobbenhaus, João Henrique Gonçalves, Franciscus Jacobus Baars, Inácio de Medeiros Delgado, Maísa Bastos Abram, Reginaldo Leão Neto, Gerson Manoel Muniz de Matos, João Orestes Schneider Santos. Geology, Tectonics and Mineral Resources of Brazil: Geographic Information System - GIS and Maps at the 1:2.500.000 scale / - Brasília : CPRM, 2001. 4 CD-Rom.

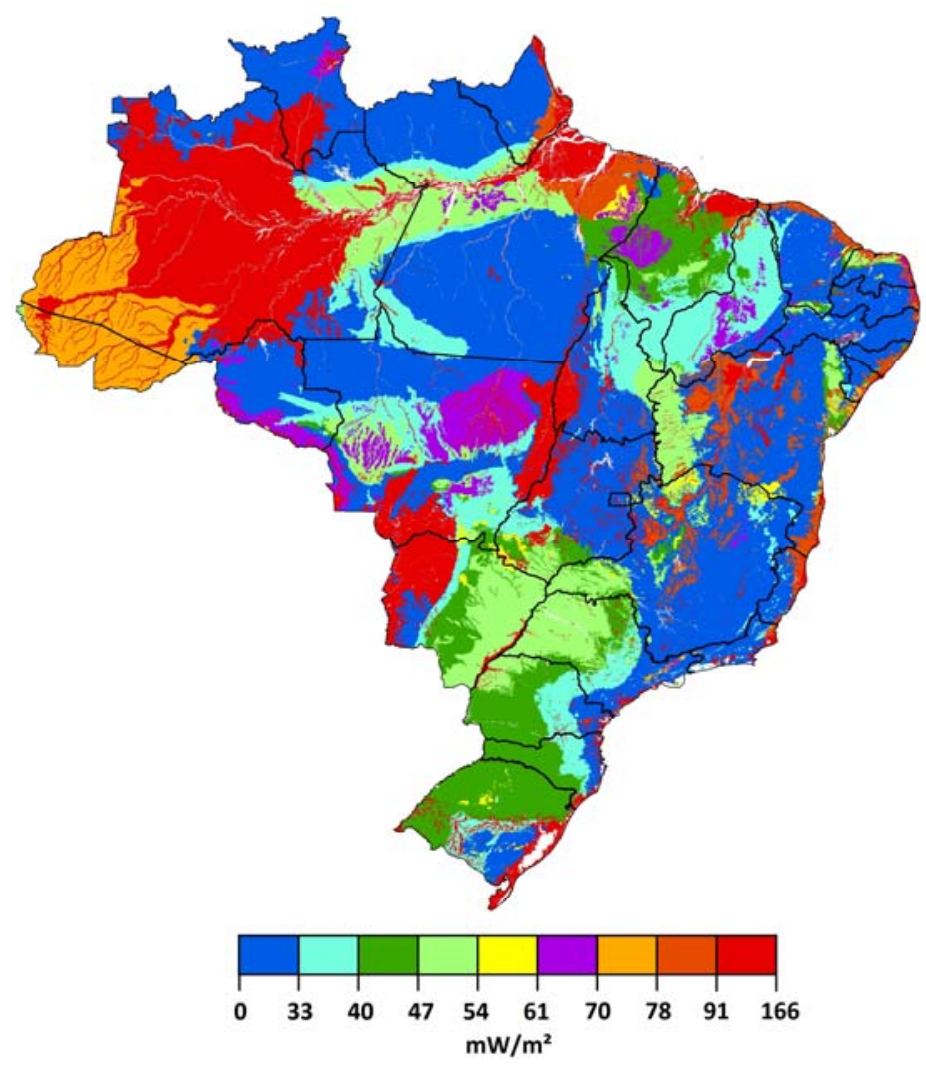

Figura (5) - Fluxo geotérmico brasileiro com base na idade das províncias tectônicas. 